\title{
Stress levels and failure modes of tantalum-clad tungsten targets at ISIS
}

\author{
Dan Wilcox, Peter Loveridge, Tristan Davenne, \\ Leslie Jones and David Jenkins
}

\section{Published version information}

Citation: D Wilcox et al. "Stress levels and failure modes of tantalum-clad tungsten targets at ISIS." Journal of Nuclear Materials, vol. 506 (2018): 76-82.

DOI: $10.1016 /$ i.jinucmat.2017.10.075

(C)2017. This manuscript version is made available under the CC-BY-NC-ND 4.0 Licence.

This version is made available in accordance with publisher policies. Please cite only the published version using the reference above. This is the citation assigned by the publisher at the time of issuing the AAM. Please check the publisher's website for any updates. 


\title{
Stress Levels and Failure Modes of Tantalum-Clad Tungsten Targets at ISIS
}

\author{
Dan Wilcox ${ }^{a, *}$, Peter Loveridge ${ }^{a}$, Tristan Davenne ${ }^{a}$, Leslie Jones ${ }^{a}$, David Jenkins ${ }^{a}$ \\ ${ }^{a}$ Science and Technology Facilities Council, Rutherford Appleton Laboratory, Harwell Campus, \\ Didcot, OX11 0QX
}

* Corresponding author. Email address: dan.wilcox@stfc.ac.uk. Postal address: Dan Wilcox, R65 1.01, Rutherford Appleton Laboratory, Harwell Campus, Didcot, OX11 0QX

\begin{abstract}
The ISIS spallation neutron source operates two tantalum-clad targets. Efforts to understand the operating conditions and lifetime limiting factors of these targets are ongoing, driven in part by premature failures of several recent TS2 targets. The Hot Isostatic Press (HIP) process used in target manufacturing is thought to introduce large residual stresses, particularly in the tantalum cladding. In addition, the pre-stressed target materials are subjected to cyclic proton beam heating and irradiation damage during operation. Manufacturing and beam-induced stresses were simulated using finite element analysis. The residual stress simulation results appear largely consistent with the findings from recent neutron diffraction measurements on an ISIS target plate. Simulations of the beam induced cyclic stress in the target, together with the available tantalum fatigue data, indicate that there is a large safety margin on the material fatigue limit and that a fatigue failure in the ISIS target cladding is therefore unlikely.
\end{abstract}

\section{Keywords}

Spallation, Target, Tantalum, Tungsten, Simulation, Residual Stress, Hot Isostatic Press, Cyclic Loading, Fatigue Life, Radiation Damage 


\section{Introduction}

The ISIS pulsed neutron source was originally operated from 1984 with a depleted uranium neutronproducing target, but in the early 1990's the target material was changed to tantalum, and then in 2001 to tantalum-clad tungsten [1]. Since 2008 ISIS has been running a second target station (TS2), again using a tantalum clad tungsten target, while continuing to run the first target station (TS1) [2]. Tantalum-clad tungsten targets have also been used at KENS [3] and LANSCE [4], and are proposed for CSNS [5] and the second target station at SNS [6]. Both materials have high atomic number and therefore high neutron yield, and as they are both refractory metals they retain good structural properties even at high temperature. Tungsten has higher neutron yield than tantalum, but suffers from rapid corrosion in irradiated water [4]. The role of the tantalum cladding is therefore to provide a corrosion resistant barrier between the tungsten and the coolant. A relatively thin cladding layer is desirable in order to minimise the fraction of tantalum/tungsten in the target, leading to improved neutron yield and a reduction in decay heat [7].

The ISIS TS1 target consists of 12 plates and operates at $160 \mathrm{~kW}$ beam power, whereas the TS2 target is a solid rod target operating at $32 \mathrm{~kW}$ beam power. A comparison between the targets is shown in Figure 1. The design lifetime for both targets is 5 years. TS1 targets reliably last 4-5 years, after which the thermocouples which monitor plate core temperatures fail and the target must be replaced. This has been the failure mode for all of the tantalum-clad tungsten TS1 targets; there have been no mechanical failures. TS2 targets currently have an average lifetime of 1.5 years, after which activity levels in the cooling water rise above acceptable levels and the target must be replaced. This is thought to be due to the heavy water coolant breaching the cladding through welded joints and corroding the tungsten core. Gamma spectrum analysis of the water filters indicates that it is tungsten rather than tantalum causing the activation issue, which supports this conclusion. Several issues with the current TS2 welding process were identified, and a new target design is in development which should prevent this failure mode from occurring in future. The engineering assurance study presented here was carried out to better understand the manufacturing and operational stress levels in the target materials.

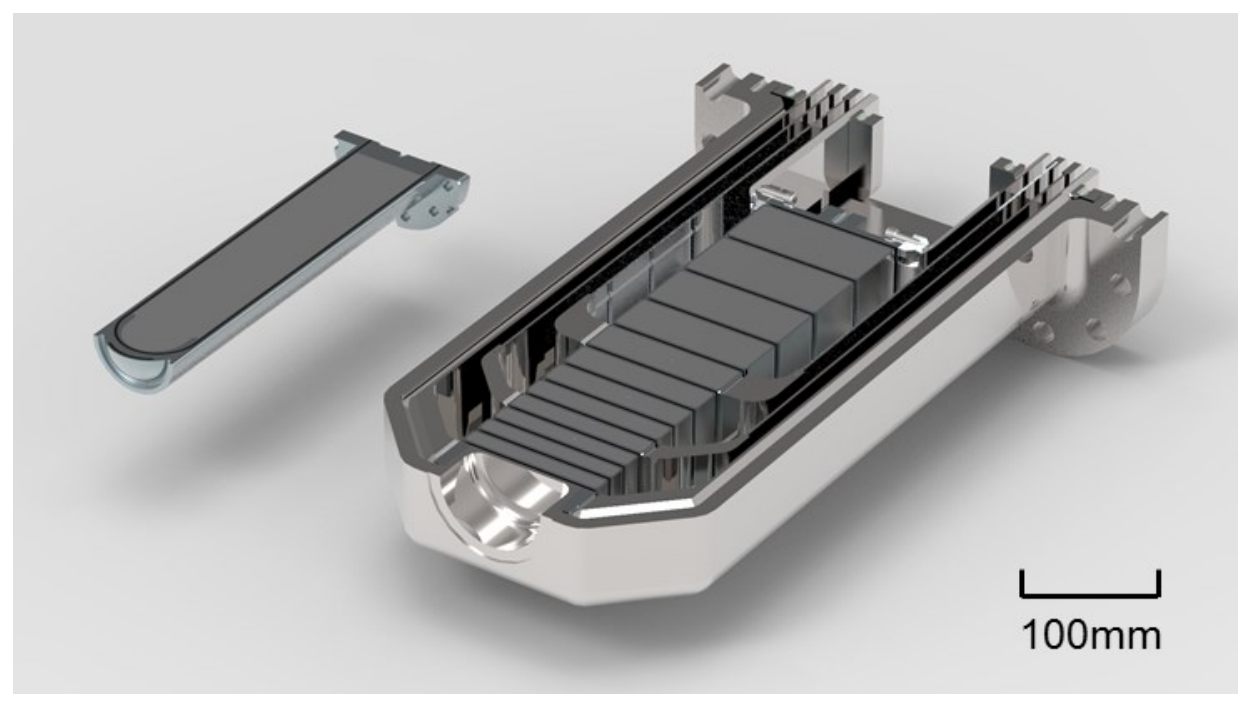

Figure 1: Cross section of ISIS targets; TS2 (left) and TS1 (right) 


\section{ISIS Target Manufacturing Process}

\subsection{Process Overview}

TS1 and TS2 targets are manufactured using similar methods. In both cases the Hot Isostatic Press (HIP) process is used to bond the cladding onto the core, ensuring a good thermal connection. The same method is widely used at other leading spallation facilities [3] [4]. The tantalum cladding consists of several parts which are assembled around the tungsten core prior to the HIP, and electron beam (EB) welded together under vacuum to form a sealed tantalum can with the tungsten core inside.

The target assembly is then put through a HIP cycle, as shown in Figure 2. High temperature and pressure are applied to the target assembly, forming a bond between the cladding and core. The ISIS HIP cycle uses a peak temperature of $1200^{\circ} \mathrm{C}$ and a peak pressure of $140 \mathrm{MPa}$, which are held for 2 hours. Note that the chosen peak temperature and pressure are somewhat lower than those reported elsewhere [3] [4]. The cladding deforms plastically under the pressure and conforms to the geometry of the tungsten core. The $1200^{\circ} \mathrm{C}$ maximum temperature was chosen to be high enough to relieve stress and form a reliable bond, but not so high as to cause significant grain growth. As the clad target cools below the stress relieving temperature, residual stress builds up due to differential thermal contraction. A final machining and grinding process is carried out to achieve dimensional accuracy. For the TS1 target each plate is HIPed and machined separately before being welded together to form the target stack.

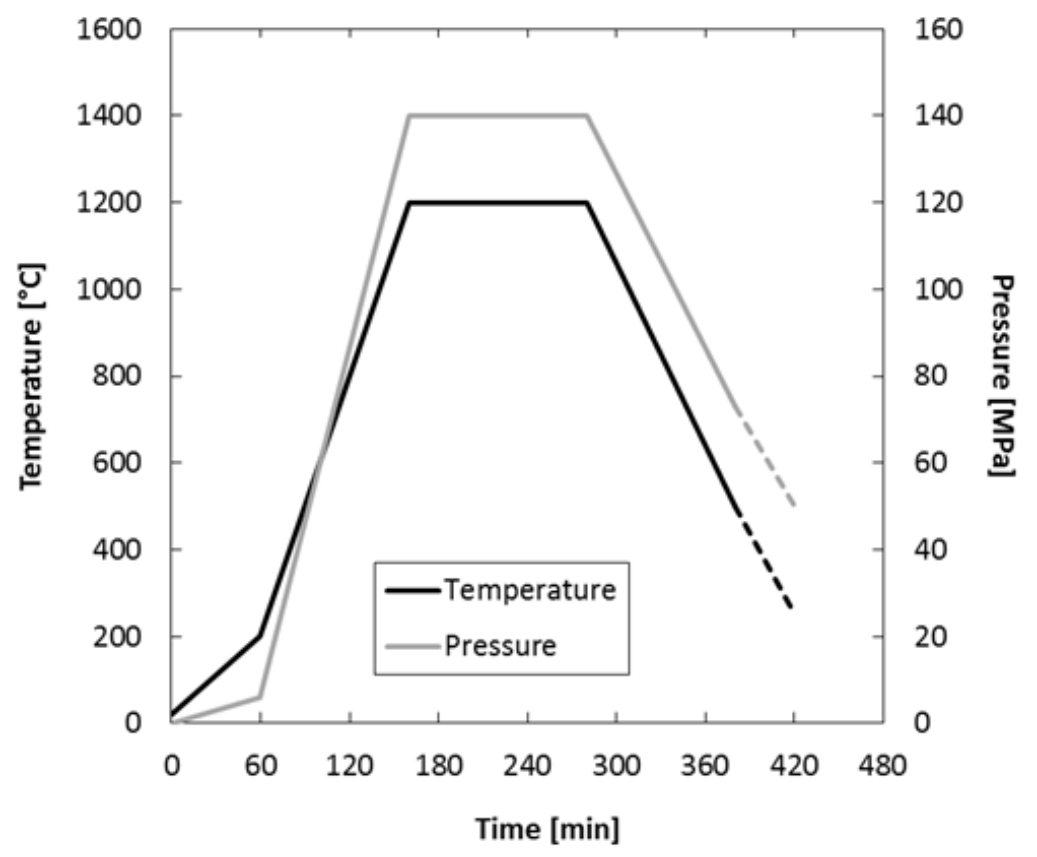

Figure 2: A typical ISIS HIP cycle 
It is assumed that the stress from EB welding and HIP pressure is completely relieved during the HIP process. Stress from differential thermal contraction during HIP cooldown is assumed to be relieved at high temperatures, but below a certain 'lock-in' temperature stress starts to build up. This lock-in temperature is estimated to be around $500^{\circ} \mathrm{C}$, but the exact value is uncertain. Stress due to final machining and plate welding is assumed to be small compared to the stress from differential thermal contraction, and is ignored in our simulations.

\subsection{Simplified Residual Stress Calcullation}

Consider the classical case of a composite layered plate subject to a uniform change in temperature. If the layup is symmetrical, e.g. a tungsten plate clad by the same thickness of tantalum on either side (Figure 3), then the composite plate will not bend as it heats or cools. A one dimensional version of this problem is included in many engineering textbooks, e.g. [8]. Ignoring edge effects, the resulting stress state for a uniform reduction in temperature ' $\Delta T$ ' is that of uniform in-plane tension in the tantalum cladding ' $\sigma_{\mathrm{Ta}}$ ', and uniform in-plane compression in the tungsten core ' $\sigma_{\mathrm{w}}$ '. The materials are initially stress-free and bonded together, so the strain is the same for each. There is no external force, so the sum of internal forces must be equal. The stress in each part depends on the cross-section areas ' $A_{1}, A_{2}$ ' and material properties as follows;

$$
\sigma_{1}=\frac{\left(\alpha_{2}-\alpha_{1}\right) \Delta T}{\left(\frac{1}{E_{1}}+\frac{A_{1}}{A_{2}} \frac{1}{E_{2}}\right)}
$$

To extend this to a 2D plate, assume stress through the plate thickness is negligible, and stress in both in-plane directions is equal. Strain in one direction is a function of all three stress components;

$$
\varepsilon_{x}=\frac{\sigma_{x}}{E}-\frac{v}{E}\left(\sigma_{y}+\sigma_{z}\right)
$$

In the 2D plate case, $\sigma_{x}=\sigma_{y}$ and $\sigma_{z}=0$, therefore;

$$
\varepsilon_{x}=\varepsilon_{y}=\sigma_{x} \frac{(1-v)}{E}
$$

From Eq.1 and Eq.3, and assuming unit width, stresses in the composite plate depend on the layer thicknesses ' $\mathrm{t}_{\mathrm{T}}, \mathrm{t}_{\mathrm{W}}$ ' and material properties as follows;

$$
\begin{gathered}
\sigma_{W}=\frac{\Delta T\left(\alpha_{T a}-\alpha_{W}\right)}{\left[\frac{\left(1-v_{W}\right)}{E_{W}}+\frac{t_{W}}{t_{T a}} \frac{\left(1-v_{T a}\right)}{E_{T a}}\right]} \\
\sigma_{T a}=\frac{\Delta T\left(\alpha_{W}-\alpha_{T a}\right)}{\left[\frac{\left(1-v_{T a}\right)}{E_{T a}}+\frac{t_{T a}}{t_{W}} \frac{\left(1-v_{W}\right)}{E_{W}}\right]}
\end{gathered}
$$

It is often the case that the tantalum cladding is much thinner than the underlying tungsten block. In this case the stress in the core is small and the stress in the cladding approaches; 


$$
\sigma_{T a}=\frac{\Delta T E_{T a}\left(\alpha_{W}-\alpha_{T a}\right)}{\left(1-v_{T a}\right)}
$$

Applying the material properties listed in Table 1 to Equation 6 it is observed that a temperature change of only $384^{\circ} \mathrm{C}$ is sufficient to drive the tantalum cladding to its yield stress of $200 \mathrm{MPa}$. It is therefore expected that the cladding will be stressed beyond its yield point during the post-HIP cool down.

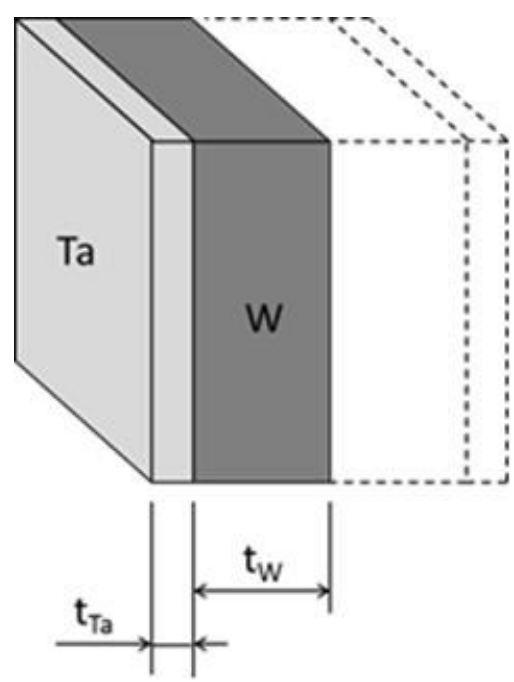

Figure 3: A composite tantalum clad tungsten plate with symmetrical layup

Table 1: Properties of tantalum and tungsten at room temperature

\begin{tabular}{lccc}
\hline Property & Symbol & Tungsten & Tantalum \\
\hline Density (kg/m^3) & $\rho$ & 19250 & 16600 \\
Young's Modulus (GPa) & $\mathrm{E}$ & 398 & 188 \\
Poisson's Ratio (-) & $\mathrm{v}$ & 0.28 & 0.35 \\
Instantaneous CTE (/K) & $\alpha$ & $4.50 \mathrm{E}-06$ & $6.30 \mathrm{E}-06$ \\
Specific Heat Capacity (J/kg.K) & $\mathrm{C}_{\mathrm{p}}$ & 128.3 & 139.0 \\
Thermal Conductivity (W/m.K) & $\mathrm{k}$ & 174.9 & 57.2 \\
Yield Strength (MPa) & $\sigma_{\mathrm{Y}}$ & $\mathrm{N} / \mathrm{A}$ (Brittle at RT) & 200 \\
Ultimate Strength (MPa) & $\sigma_{\mathrm{UTS}}$ & 550 & 270 \\
\hline
\end{tabular}

\subsection{FEA Simulation of Residual Stress}

A model was created of the current ISIS TS1 target using the Finite Element Analysis (FEA) code ANSYS [9]. Figure 4 shows the internal geometry of the current ISIS TS1 target. Only the front two plates were modelled, as they receive the highest power density. Horizontal and vertical symmetry planes were applied, so only a quarter of each plate was modelled. The geometry and mesh used is shown in Figure 5. Material properties used are listed in Table 1. Tantalum plasticity was simulated using a yield strength of $200 \mathrm{MPa}$, based on tensile test data for ISIS tantalum [10]. HIP residual stress was simulated assuming a $500^{\circ} \mathrm{C}$ lock-in temperature; results are shown in Figure 6 . All of the thin 
sections of tantalum cladding are now at the yield stress (200MPa). Investigating the principal stress components reveals that the residual stress is tensile in the tantalum cladding and compressive in the tungsten core. A sensitivity study to 'lock-in' temperature ' $T_{L}$ ' was carried out. At $T_{L}=400^{\circ} \mathrm{C}$ and above the cladding has uniformly yielded, as predicted by the calculation in section 2.2. At higher 'lock-in' temperatures the stress profile remains the same but the total strain continues to increase, from $0.16 \%$ at $T_{L}=400^{\circ} \mathrm{C}$, up to $0.5 \%$ in the worst case $\left(T_{L}=1200^{\circ} \mathrm{C}\right)$. Tensile tests on tantalum samples from ISIS have shown that it is highly ductile, with strain to failure values greater than $30 \%$ [10].
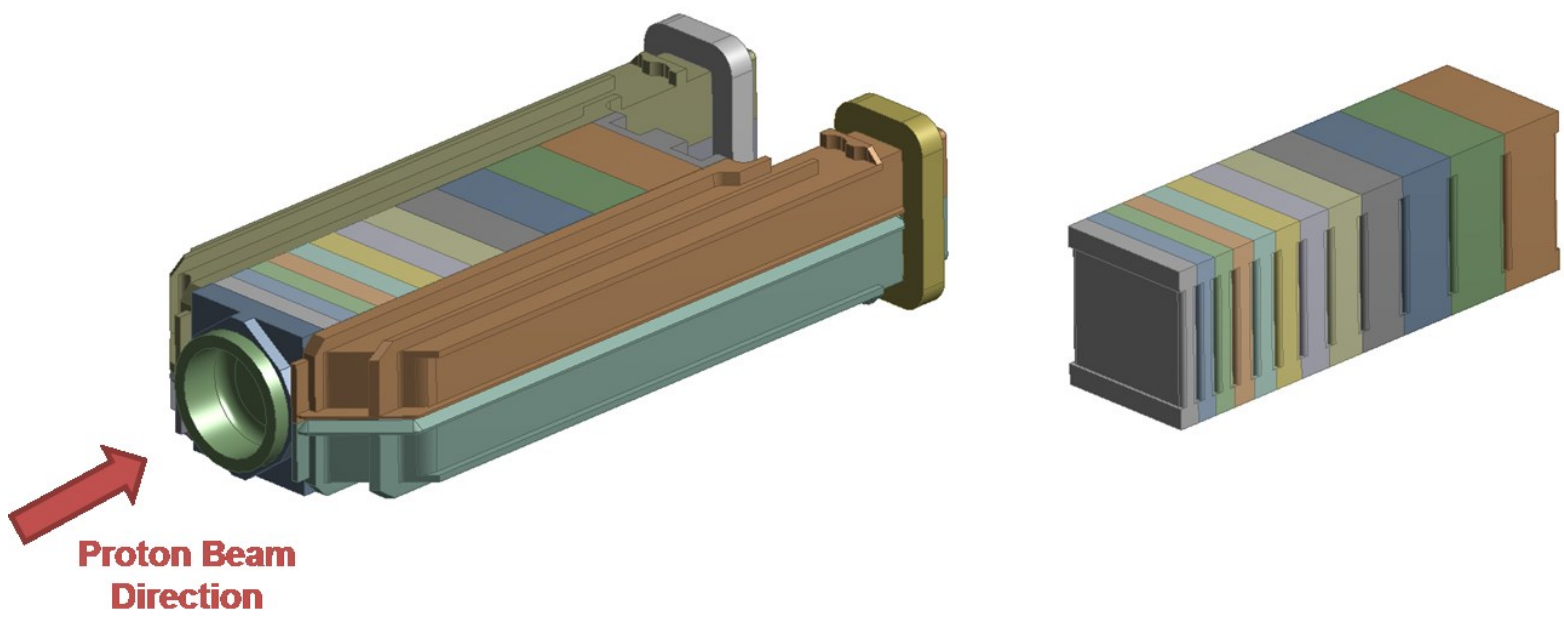

Figure 4: ISIS TS1 target geometry (left), detail of target plate stack (right)

\section{Proton Beam Direction}

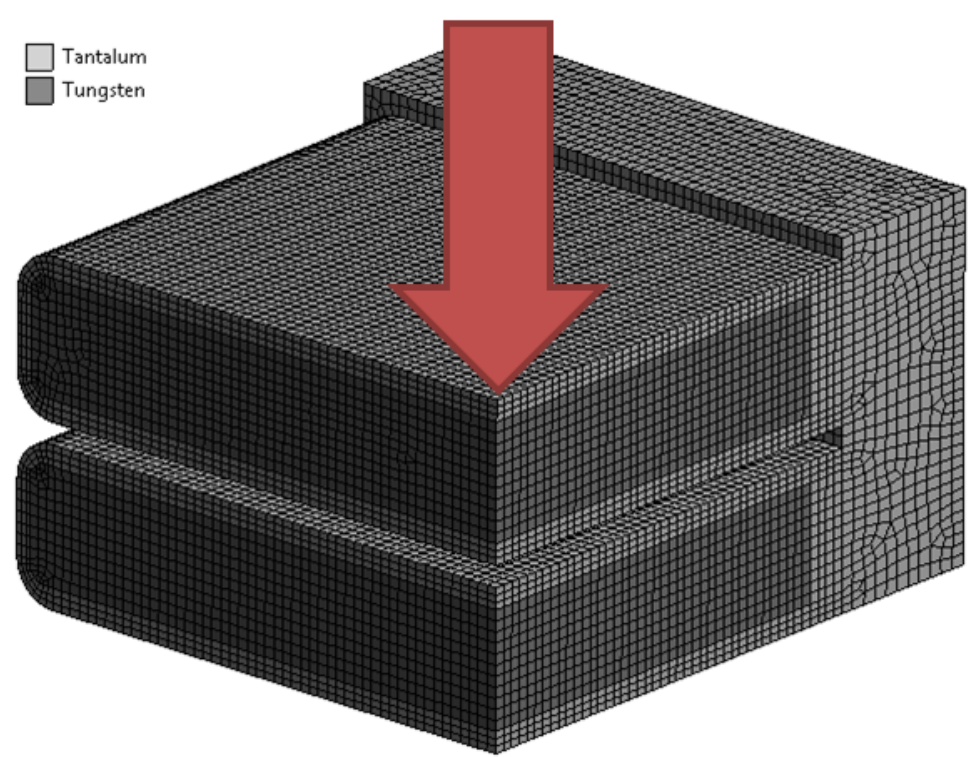

Figure 5: Geometry and mesh for one quarter symmetry model of TS1 target plates 1 and 2 


\section{Unit Pa}
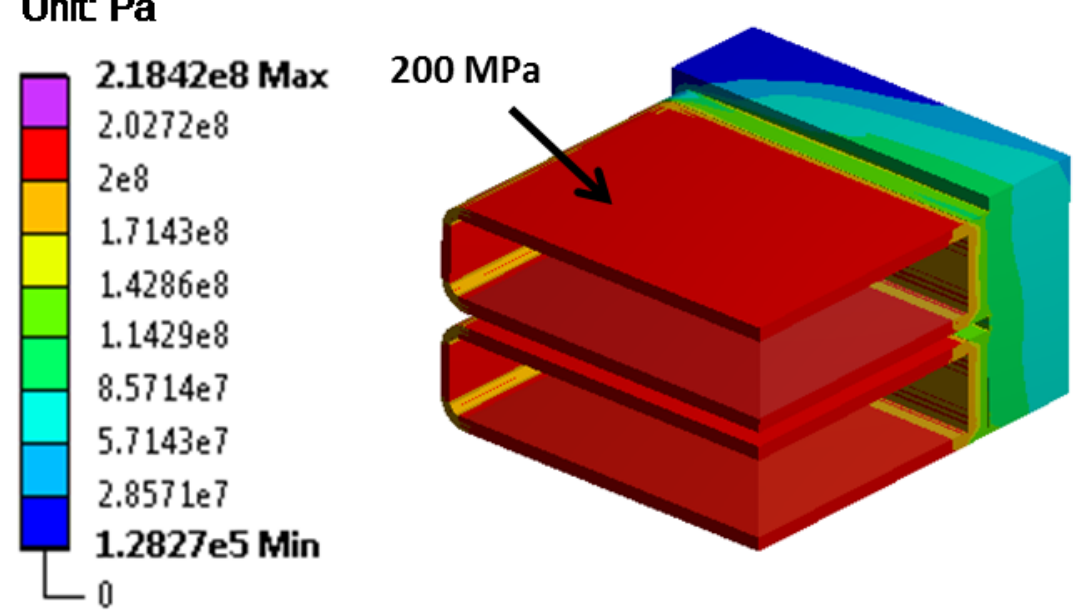

Figure 6: Von Mises stress (Pa) in tantalum only, in ISIS TS1 target plates 1 and 2 as a result of HIPing with a $500^{\circ} \mathrm{C}$ lock-in temperature

\subsection{Measuring the Residual Stress}

The preceding analysis of residual stress depends entirely on the assumed value of lock-in temperature, which cannot be measured directly. However, the ENGIN-X neutron diffraction instrument at ISIS [11] was used to make preliminary measurements of residual strain in a clad ISIS plate [12]. Neutron diffraction measures spacing between atoms and uses this to determine elastic strain. Plastic strain cannot be measured with neutron diffraction. The measured elastic strains were broadly consistent with the cladding being uniformly at the yield stress as predicted. However, this cannot be fully confirmed as measurements were only made in two rather than all three orthogonal directions and therefore the full tri-axial strain state cannot be reconstructed. ENGIN-X directional elastic strain results are shown in Figure 7 and ANSYS simulated elastic strains for the same case are shown in Figure 8. The strain distribution is similar, and the strain values are relatively close, particularly in the tantalum. Some of the differences may be due to the way the sample was prepared; the HIPed plate was cut into quarters before measurements were taken, which may have relieved some of the strain. The experiment was calibrated using measurements on a nominally unstrained sample of the same material. In this case, the material used was taken from the same HIPed plate and stress relieved, although there is no guarantee it was returned to a completely unstressed condition. Some very high localised strains were measured in the tungsten which do not appear in the simulation; these may be due to the effect of HIPing on voids or impurities in the asreceived tungsten.

A follow-up experiment is planned for 2017 , which will attempt to reduce uncertainties in the initial result by measuring all three strain components, using a sample which is not cut, and taking calibration measurements from a separate piece of material which has not been HIPed. Because neutron diffraction cannot measure plastic deformation, this will not allow us to determine the 'lock-in' temperature exactly; only to determine whether it is higher than $400^{\circ} \mathrm{C}$, in which case the cladding is fully yielded. An alternative method may be to design an asymmetric plate geometry which would deflect in proportion to the residual strain (including elastic and plastic strain), allowing the 'lock-in' temperature to be inferred. 


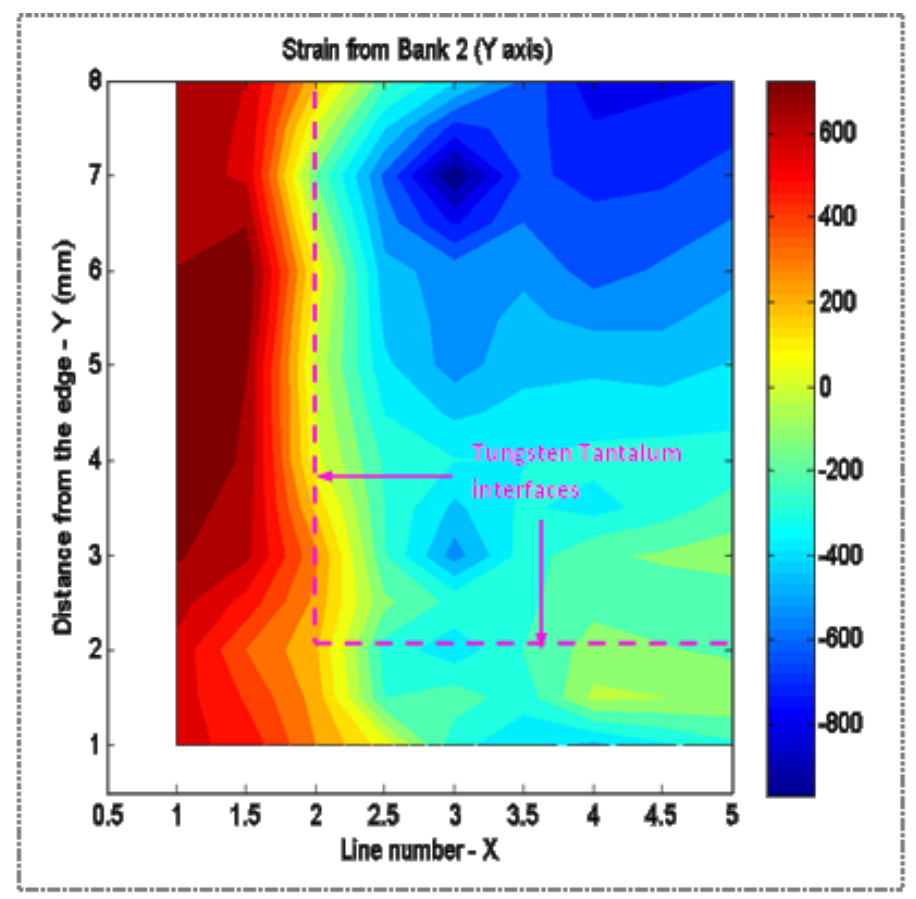

Figure 7: ENGIN-X strain measurement (microstrain) in vertical (y) direction in one corner of a TS1 target plate. Reproduced from Y. Ma et al. [12].

\section{Unit Microstrain}
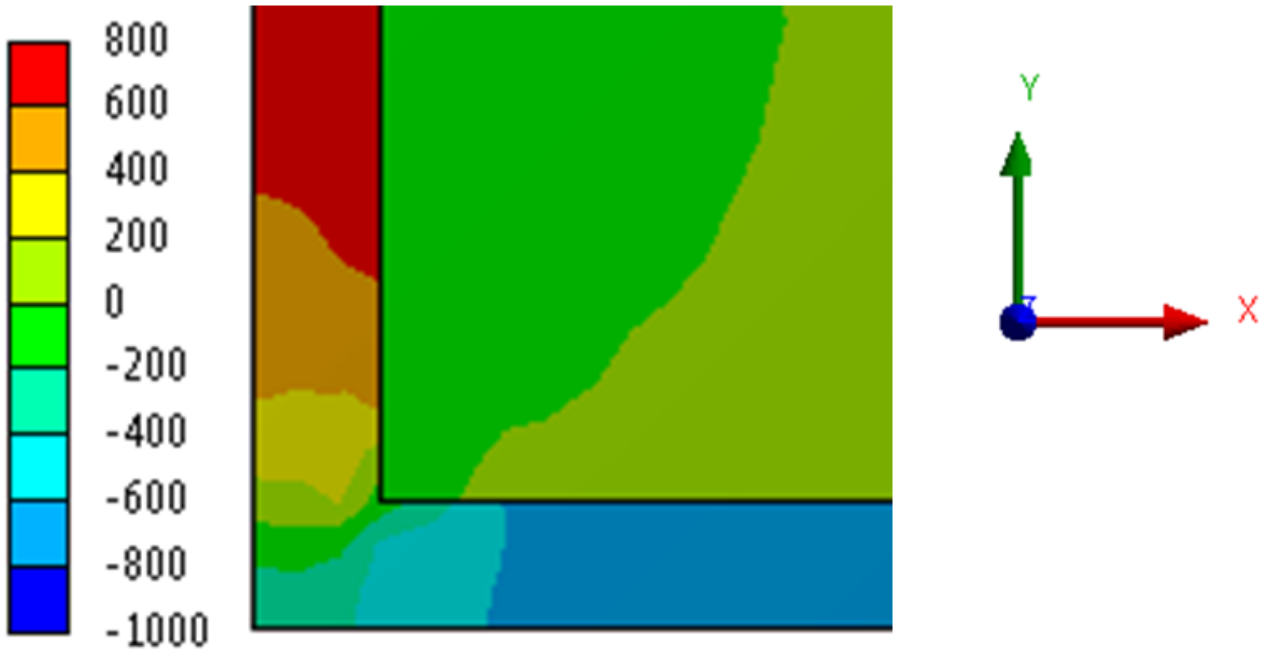

Figure 8: ANSYS simulation of elastic strain (microstrain) in vertical (y) direction for the same case as Figure 7. 


\section{ISIS Target Operating Conditions}

\subsection{Steady State Temperature}

The maximum proton beam current which can be delivered to ISIS TS1 is $200 \mu \mathrm{A}$. Heat deposition due to the $200 \mu \mathrm{A}$ proton beam was simulated in the Monte Carlo particle tracking code FLUKA [13]; the results are shown in Figure 9. The beam heating is concentrated in the centre of the target, and reduces radially due to the Gaussian profile of the beam. ANSYS was used to simulate heat transfer from the plate into the flowing heavy water coolant. The resulting temperature distribution is shown in Figure 10; the peak temperature is about $200^{\circ} \mathrm{C}$ in tungsten, $175^{\circ} \mathrm{C}$ in tantalum. There are large temperature gradients from the target core to the edges, which will give rise to significant thermal stresses.

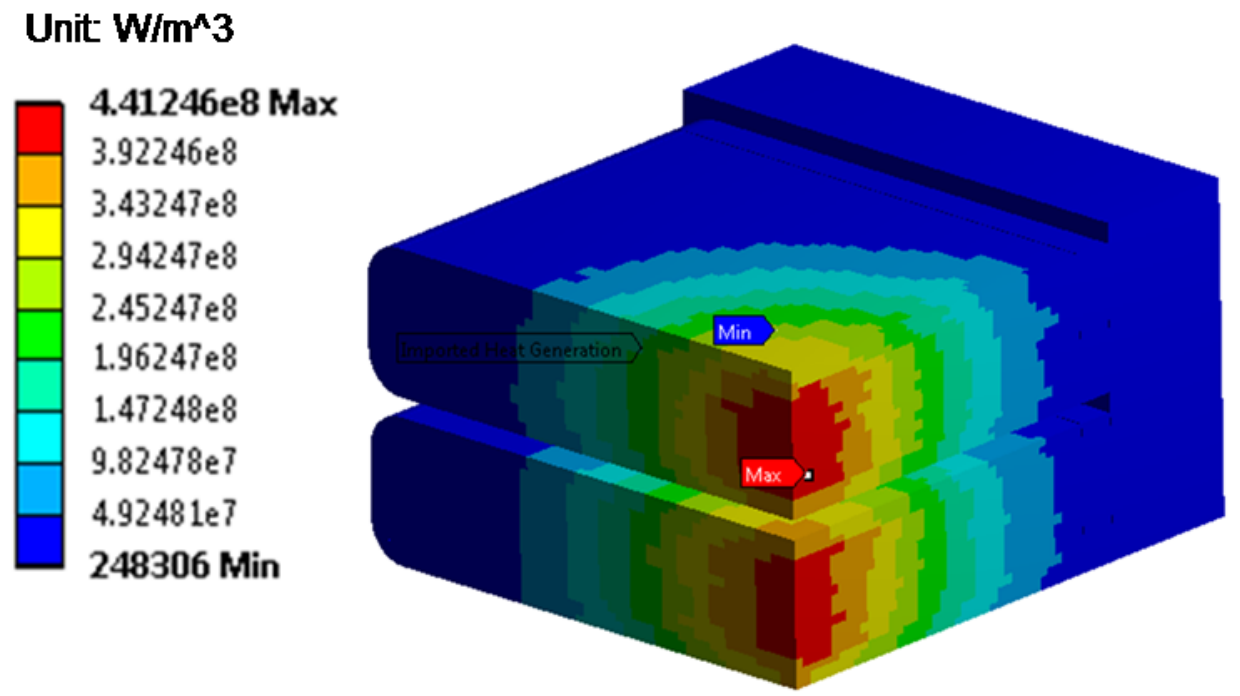

Figure 9: Time-averaged heat generation $\left(\mathrm{W} / \mathrm{m}^{\wedge} 3\right)$ due to $200 \mu \mathrm{A}$ proton beam in ISIS TS1 target plates 1 and 2

Unit ${ }^{\circ} \mathrm{C}$
\begin{tabular}{|l}
$\mathbf{2 0 1 . 2 2}$ Max \\
182.88 \\
164.55 \\
146.21 \\
127.88 \\
109.55 \\
91.212 \\
72.878 \\
54.544 \\
36.209 Min
\end{tabular}

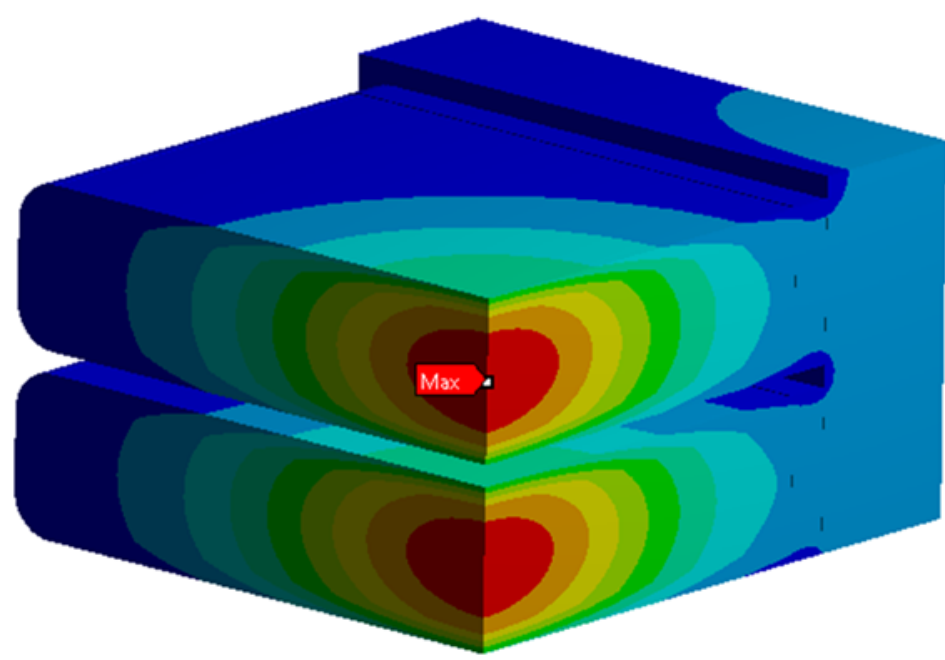

Figure 10: Steady state operating temperature $\left({ }^{\circ} \mathrm{C}\right)$ due to $200 \mu \mathrm{A}$ proton beam in ISIS TS1 target plates 1 and 2 


\subsection{Steady State Stress}

ANSYS was used to calculate the steady-state target operating stress, which is a combination of HIP residual stress and beam-induced thermal stress. Results are shown in Figure 11; beam heating partially relieves the residual stress at the target centreline, however the maximum stress is still 200MPa due to residual stress. Over time, the residual manufacturing stress may be relieved by radiation-induced creep. However, the operating temperature of the tantalum is fairly low so the rate of radiation-induced creep is expected to be relatively low.
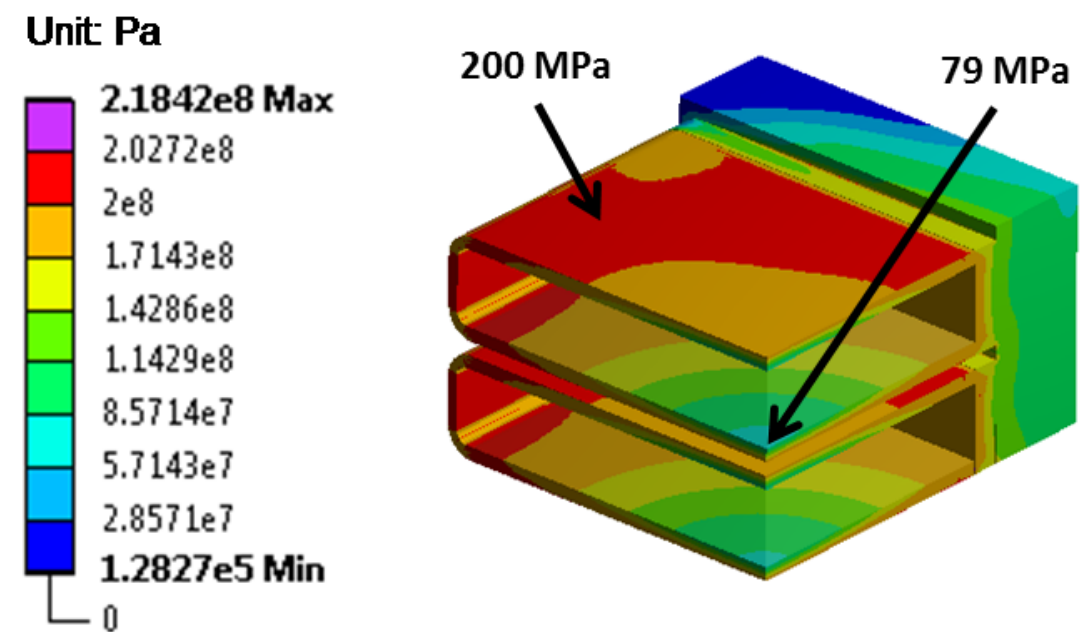

Figure 11: Von Mises stress (Pa) in tantalum only, in ISIS TS1 target plates 1 and 2 as a result of $\mathrm{HIPing}$ with a $500^{\circ} \mathrm{C}$ lockin temperature followed by steady state operation with $200 \mu \mathrm{A}$ beam current

A similar FEA simulation was carried out for the ISIS TS2 target. A summary of stress results for both targets is given in Table 2. In both cases the simulation included residual stress due to HIPing with a lock-in temperature of $500^{\circ} \mathrm{C}$. Despite the differences in geometry, the results are very similar for both targets. In both cases the tantalum has yielded and the HIP residual stress is the largest contribution to the tantalum stress. The simulated total strain in tantalum is relatively low, less than $0.5 \%$ in each case, well below the minimum strain to failure value of $30 \%$ [10].. ISIS design calculations assume that room temperature tungsten is brittle, with an ultimate tensile strength of $550 \mathrm{MPa}$. Tietz and Wilson [14] report various ultimate tensile strengths depending on manufacturing method, but all are higher than 550MPa at room temperature, so the ISIS limit appears to be conservative. Simulated stress levels in tungsten are much lower than this, giving a large safety margin. Additionally, the cladding will provide some structural support for the core. The HIP residual stress may be beneficial in this respect; the core is under compressive residual stress which will improve resistance to fatigue and brittle fracture. Steady state stresses alone are not expected to cause failure of the cladding or core. The cladding is of more concern than the core, as it is a thin part under highly tensile residual stress, which forms an essential barrier between the corrosion-prone tungsten core and the heavy water coolant. 
Table 2: Steady state stress results from ANSYS simulations of current ISIS targets, for the combination of residual manufacturing stress and beam-induced thermal stress

\begin{tabular}{lcc}
\hline Result & TS1 & TS2 \\
\hline Tungsten Stress (MPa) & 207 & 191 \\
Tantalum Stress (MPa) & $200^{*}$ & $200^{*}$ \\
Tantalum Total Strain (\%) & 0.40 & 0.38 \\
\hline
\end{tabular}

*Stress in tantalum is limited to 200MPa as this is the yield strength of the material

\subsection{Transient and Fatigue Simulations}

The FEA simulations for each target included transient thermal stresses as a result of the pulsed nature of the beam, combined with the residual stress state from HIPing. The residual stress is compressive in tungsten; due to this, and the high tensile strength of tungsten, fatigue failure of the core is considered unlikely. However, the residual stress in tantalum is highly tensile, so fatigue life of the cladding was investigated in detail. The transient stresses are relatively low, but the mean stresses can be very high due to the residual HIP stress. Any combination of stress amplitude and mean stress can be replaced by an equivalent, fully reversed stress amplitude which will give the same fatigue life, by using the Goodman relation [15];

$$
\sigma_{f}=\frac{\sigma_{a}}{\left(1-\frac{\sigma_{m}}{\sigma_{U T S}}\right)}
$$

Where $\sigma_{\mathrm{f}}$ is the Goodman equivalent fully reversed stress amplitude, $\sigma_{\mathrm{a}}$ is the stress amplitude, $\sigma_{\mathrm{m}}$ is the mean stress, and $\sigma_{U T S}$ is the ultimate tensile strength. The ultimate tensile strength of tantalum was taken to be 270MPa, based on tensile testing of post-HIP ISIS tantalum [10].The Goodman relation is a commonly used design criterion, considered to be conservative for ductile materials such as tantalum [15].

Two types of transient loading were considered; the pulsed nature of the beam, and beam trips in which an accelerator fault results in loss of beam allowing the target to cool to room temperature and cause a larger thermal cycle. Table 3 shows the maximum equivalent stress amplitude for each load case, on each ISIS target. The design lifetime for ISIS targets is 5 years. The total number of stress cycles in a target lifetime was estimated by reviewing past operating data. Taking into account both planned shutdowns and unplanned beam trips, ISIS facility uptime was found to be $45 \%$ on average over the last few years. Beam trips occur on average once every $\approx 100$ minutes; i.e. a frequency of $1.7 \mathrm{E}-04 \mathrm{~Hz}$. Table 4 shows the estimated number of stress cycles. The stress amplitude due to beam pulse cycles is low for all ISIS targets, but the total number of cycles in a 5 year lifetime is very high. Beam trips are less frequent, but stress amplitudes are larger. 
Table 3: Goodman equivalent stress amplitudes (MPa) in tantalum, from ANSYS simulations with residual stress included

\begin{tabular}{lcc}
\hline Case & TS1 & TS2 \\
\hline Beam Pulse & 4.2 & 17.5 \\
Beam Trip & 113 & 98 \\
\hline
\end{tabular}

Table 4: Estimated number of stress cycles experienced by ISIS targets, assuming $45 \%$ facility uptime. The frequency of beam trips is the same for TS1 and TS2 targets.

\begin{tabular}{lccc}
\hline Case & Frequency $(\mathbf{H z})$ & Cycles per year & Cycles per $\mathbf{5}$ year target lifetime \\
\hline Pulses TS1 & 40 & $5.4 \mathrm{E}+08$ & $2.7 \mathrm{E}+09$ \\
Pulses TS2 & 10 & $1.3 \mathrm{E}+08$ & $6.7 \mathrm{E}+08$ \\
Beam trips & $1.7 \mathrm{E}-04$ & $2.2 \mathrm{E}+03$ & $1.1 \mathrm{E}+04$ \\
\hline
\end{tabular}

\subsection{Review of Tantalum Fatigue Data}

Available fatigue data for tantalum is very limited. ISIS targets and other spallation applications will cause high-cycle fatigue loading of pure tantalum. Three relevant data sources were found; Papakyriacou et al. [16], Helebrant and Stevens [17], and Bornemann and Gela [18]. There is a significant variation in the endurance limits reported in these papers, as shown in Table 5. Factors such as specimen geometry, cold working and test frequency have a large impact on the endurance limit. There is also a large variation in yield and ultimate tensile strengths, suggesting significant differences in material properties between batches, possibly due to impurities or manufacturing methods. The effects of impurities and manufacturing methods on fatigue life have not been studied in detail in any of the reports collected here. One general conclusion which can be drawn is that the endurance limit of tantalum is very high compared to the yield strength. Transient stresses modelled for ISIS targets are well within the reported endurance limits (see Table 3). This initial analysis suggests that failure of the cladding due to fatigue alone is unlikely. Radiation damage will reduce the fatigue life by an amount which is difficult to predict, but there is a large safety margin on the tantalum endurance limits quoted. 
Table 5: Summary of reported high-cycle fatigue tests on pure tantalum

\begin{tabular}{|c|c|c|c|c|c|}
\hline Authors & Year & Test Details & $\begin{array}{c}\text { Test } \\
\text { Frequency }(\mathrm{Hz})\end{array}$ & $\begin{array}{l}\text { Number } \\
\text { of Cycles }\end{array}$ & $\begin{array}{l}\text { Endurance } \\
\text { Limit (MPa) }\end{array}$ \\
\hline \multirow{4}{*}{$\begin{array}{l}\text { Papakyriacou et al. } \\
\text { [16] }\end{array}$} & 2001 & Rotating bend, annealed tantalum & 100 & $2 \mathrm{E} 8$ & $270 \pm 30$ \\
\hline & & Ultrasonic, annealed tantalum & 20,000 & $2 \mathrm{E} 8$ & $335 \pm 15$ \\
\hline & & Rotating bend, cold worked tantalum & 100 & $2 \mathrm{E} 8$ & $290 \pm 35$ \\
\hline & & Ultrasonic, cold worked tantalum & 20,000 & $2 \mathrm{E} 8$ & $365 \pm 10$ \\
\hline \multirow{2}{*}{$\begin{array}{l}\text { Bornemann and Gela } \\
\text { [18] }\end{array}$} & 1953 & Universal fatigue machine & Unknown & $2 \mathrm{E} 7$ & 240 \\
\hline & & Rotating beam fatigue machine & Unknown & $2 \mathrm{E} 7$ & $\approx 440$ \\
\hline $\begin{array}{l}\text { Helebrant and Stevens } \\
\text { [17] }\end{array}$ & 1971 & Constant stress amplitude & 20 & $5 \mathrm{E} 6$ & $\approx 200$ \\
\hline
\end{tabular}

\subsection{Review of Tantalum Irradiation Data}

There is only limited data on irradiation effects in Tantalum. The main radiation effect which could limit the life of ISIS targets is thought to be loss of ductility. Tensile tests were carried out on samples cut from a spent ISIS Target at Forschungszentrum Jülich [19]. After $800 \mathrm{MeV}$ proton irradiation up to 11 displacements per atom (dpa), the tantalum retained significant ductility. Other tantalum specimens were irradiated using reactor neutrons at the High Flux Isotope Reactor (HFIR) [20]. After $>0.1 \mathrm{MeV}$ fast neutron irradiation up to $0.14 \mathrm{dpa}$, the tantalum was ductile at $0.04 \mathrm{dpa}$ but much more brittle after only $0.14 \mathrm{dpa}$. The significant variation in the effect of irradiation on ductility is thought to be due to the effect of impurities, particularly hydrogen and oxygen [21]. The low ductility after irradiation of the tantalum samples from HFIR is thought to be due to high oxygen levels picked up during a pre-irradiation anneal [20]. Heat treatment, grain size, and irradiation temperature may also have a significant effect. A large radiation-induced loss of ductility could threaten the integrity of the cladding, as this is expected to have a detrimental effect on fatigue life. Unfortunately, there is not enough data available to produce a quantitative value for a safe dpa limit for ISIS targets. However there are large safety margins on the material limits, and operating experience with ISIS TS1 demonstrates that targets can be run for up to 5 years without any mechanical problems in the cladding or core.

\section{Conclusions}

- A large residual stress is expected in the tantalum as a result of the HIP manufacturing process. Simulations predict that all thin sections of the cladding will exceed the yield stress, but the total strain will remain relatively low (less than $0.5 \%$ ), and since tantalum is highly ductile no failure is expected.

- Manufacturing pre-stress simulation results appear largely consistent with the findings from a recent neutron diffraction measurement of residual strain in an ISIS target plate, confirming the presence of a significant tensile residual stress in the cladding. Further 
experiments are required to determine whether or not the cladding has reached its yield stress as predicted.

- FEA simulations were carried out to determine steady state operating stress levels in ISIS TS1 and TS2 targets. Steady state stresses alone are not expected to cause failure of either target. The cladding is of more concern than the core, as it is a thin part under highly tensile residual stress, which forms an essential barrier between the corrosion-prone tungsten core and the heavy water coolant.

- Stress amplitudes and number of cycles were determined for TS1 and TS2 targets, and compared to fatigue data for tantalum. What limited data is available indicates a very high endurance limit for tantalum, giving a large safety margin against fatigue failure.

- Radiation damage is a large unknown in the present analysis. However there are large safety margins on the material limits, and operating experience with ISIS TS1 demonstrates that targets can be run for up to 5 years without any mechanical problems in the cladding or core.

\section{Acknowledgements}

This work was supported by STFC through the ISIS Neutron and Muon Source.

\section{References}

[1] D. J. S. Findlay, "ISIS - Pulsed Neutron and Muon Source," in Proceedings of PACO7, Albuquerque, 2007.

[2] D. J. S. Findlay, "High Power Operational Experience at ISIS," in Proceedings of HB2010, Morschach, 2010.

[3] M. Kawai et al., "Fabrication of a tantalum-clad tungsten target for KENS," Journal of Nuclear Materials, no. 296, pp. 312-320, 2001.

[4] A. T. Nelson, J. A. O'Toole, R. A. Valicenti and S. A. Maloy, "Fabrication of a tantalum-clad tungsten target for LANSCE," Journal of Nuclear Materials, vol. 431, p. 172-184, 2012.

[5] "Physics Design and Technology Development of CSNS Target Station and Instruments," Second CSNS International Neutron Technology Advisory Committee Review Meeting, 2010.

[6] "Technical Design Report Second Target Station," Oak Ridge National Laboratory, 2015. 
[7] Q. Yu, "Decay heat calculations for a $500 \mathrm{~kW}$ W-Ta spallation target," Nuclear Instruments and Methods B, vol. 351, pp. 41-45, 2015.

[8] P. P. Benham, R. J. Crawford and C. G. Armstrong, Mechanics of Engineering Materials, 2nd ed., Prentice Hall, 1996.

[9] ANSYS $^{\circledR}$ Mechanical Enterprise, Release 17.1, ANSYS, Inc..

[10] E. Quinn, "Material Properties Evaluation of a Hot Isostatically Pressed Tantalum Pressure Vessel for the ISIS TS-2 Target," 2012. [Online]. Available: http://pasi.org.uk/images_pasi/3/31/IWSWT11_Ta_HIP.pdf. [Accessed 27 October 2016].

[11] J. R. Santisteban et al., "ENGIN-X: a third-generation neutron strain scanner," Journal of Applied Crystallography, no. 39, p. 812-825, 2006.

[12] Y. Ma et al., "An Experiment Using Neutron Diffraction to Investigate Residual Strain Distribution in a Hot Isostatic Pressed (HIPPED) Target Plate," in Joint 3rd UK-China Steel Research Forum \& 15th CMA-UK Conference on Materials Science and Engineering, 2014.

[13] A. Ferrari et al., "FLUKA: A multi-particle transport code," no. INFN-TC-05-11, 2005.

[14] T. E. Tietz and J. W. Wilson, Behaviour and properties of refractory metals, Edward Arnold Publishers Ltd., 1965.

[15] S. Suresh, Fatigue of Materials, Cambridge University Press, 1998.

[16] M. Papakyriacou et al., "Influence of loading frequency on high cycle fatigue properties of b.c.c. and h.c.p. metals," Materials Science and Engineering: A, vol. 308, no. 12, pp. 143-152, 2001.

[17] D. R. Helebrant and R. I. Stephens, "Cyclic yield behavior of tantalum," lowa Univ. Dept. of Mechanical Engineering, 1971.

[18] A. Bornemann and T. Gela, "Studies in the Behaviour of Certain Non Ferrous Metals at Low Temperatures," 1953.

[19] J. Chen et al., "Summary of the results from post-irradiation examination of spent targets at the FZ-Juelich," Journal of Nuclear Materials, no. 318, pp. 56-69, 2003.

[20] T. S. Byun and S. A. Maloy, "Dose dependence of mechanical properties in tantalum and tantalum alloys after low temperature irradiation," Journal of Nuclear Materials, no. 377, pp. 72-79, 2008.

[21] K. J. Leonard, "Radiation Effects in Refractory Metals and Alloys," Comprehensive Nuclear Materials, vol. 4, pp. 181-213, 2012. 